\title{
Spray-deposited PEDOT:PSS for inverted organic solar cells
}

\author{
Jonas Weickert, Haiyan Sun, Claudia Palumbiny, Holger Christian Hesse, Lukas Schmidt-Mende* \\ Ludwig-Maximilians-University Munich, Department of Physics and Center for NanoScience (CeNS), Amalienstr. 54, 80799 Munich, Germany
}

Keywords:

PEDOT:PSS

P3HT:PCBM

Organic solar cell

Inverted structure

$\mathrm{TiO}_{2}$

Long-term stability

\section{Introduction}

Interest in the research field of organic solar cells is remarkably growing since Tang[1] reported the first donor acceptor junction cell in 1986 with a power conversion efficiency of about $1 \%$. Due to low production costs and predicted efficiencies beyond $10 \%$, organic solar cells offer the potential to compete with inorganic photovoltaic cells in the future [2]. In recent years, efficiencies of 5 6\% have been reported for the well known donor acceptor system of poly 3 hexyl thiophene (P3HT) and [6,6] phenyl $\mathrm{C}_{61}$ butyric acid methyl ester (PCBM) [3]. However, high efficien cies are mainly gained if several fabrication steps are performed inside a nitrogen glove box. Additionally, the widely used cell geometry utilizes aluminum or calcium metal contacts. Without encapsulation these devices cannot be operated in ambient air since the performance drops within minutes.

One attempt to increase air stability is to invert the commonly used structure by introduction of a $\mathrm{TiO}_{2}$ layer as the bottom electrode [4]. In this geometry it is possible to use noble metals as top electrodes and avoid performance losses due to top contact oxidation. Thus, solar cells can be stored and measured in air, and consecutive measurements can be performed on the same device without significant degradation, facilitating systematic research.

Best efficiencies for inverted type solar cells are gained with $\mathrm{Ag}$ top contacts. However, similar to $\mathrm{Cu}$ top contacts, the device perfor mance is not constant for bare $\mathrm{Ag}$ since the metal's work function

\footnotetext{
* Corresponding author.

E-mail address: L.Schmidt-Mende@physik.uni-muenchen.de (L. Schmidt-Mende).
}

changes with time [5]. Consequently, research becomes more complicated as time evolution effects have to be taken into account.

One possible work around is the usage of a thin layer of poly( 3,4 ethylenedioxythiophene):poly(styrene sulfonate) (PEDOT:PSS) un derneath the top contact. PEDOT:PSS is a conductive polymer with the potential to substitute metal contacts in the future and allow low cost production, roll to roll processing and the fabrication of large area solar panels [ $\left[\begin{array}{ll}6 & 8\end{array}\right]$.

PEDOT:PSS exhibits a constant work function of $5.0 \mathrm{eV}$ and is commonly used in non inverted organic solar cells to enhance the hole collecting behavior of the bottom electrode. The use of PEDOT:PSS is also reported in inverted solar cells, where the layer is mostly spincoated at $50006000 \mathrm{rpm}[9,10]$. However, PEDOT:PSS has to be applied on top of the active layer and wetting of the organic material is often insufficient due to the hydrophilic character of the PEDOT:PSS suspension in aqueous solution.

Here we report on efficient inverted P3HT PCBM solar cells with lifetimes exceeding 100 days for storage under ambient conditions in the dark. Cell fabrication is performed completely without the use of a nitrogen glove box. We study the influence of a PEDOT:PSS interlayer on device performance and device time evolution. A novel deposition method is presented that allows the controlled deposi tion of a thin, homogenous PEDOT:PSS film onto organic materials.

\section{Experimental}

\subsection{Device fabrication}

Solar cells are produced on ITO coated glass substrates purchased from Kintech $(10 \Omega / \square)$. ITOs are cleaned consecutively by ultrasonication for $30 \mathrm{~min}$ in acetone, $30 \mathrm{~min}$ in 2 propanol, 
$30 \mathrm{~min}$ in acetone and $30 \mathrm{~min}$ in 2 propanol. Substrates are rinsed with ethanol, dried in a nitrogen stream and treated for $7 \mathrm{~min}$ in a Diener Femto plasma cleaner. Approximately $100 \mathrm{~nm}$ of $\mathrm{TiO}_{2}$ is deposited by spray pyrolysis at $450{ }^{\circ} \mathrm{C}$ from a $1: 10$ solution of di isopropoxytitanium bis(acetylacetonate) in ethanol (Sigma Aldrich) and samples are cured at this temperature for $15 \mathrm{~min}$. The heating and cooling rates are 30 and $2.5^{\circ} \mathrm{C} / \mathrm{min}$, respectively. $\mathrm{TiO}_{2}$ layers are ultrasonicated for $5 \mathrm{~min}$ in acetone, rinsed with ethanol and dried in a nitrogen stream. P3HT and PCBM are used as bought from Merck and Nano C, respectively. P3HT and PCBM solutions are prepared in chlorobenzene (Sigma Aldrich, high purity) at 30 and $24 \mathrm{mg} / \mathrm{ml}$, respectively, mixed at a $1: 1$ volume ratio and spincoated at 600 rpm. For PEDOT:PSS (H.C. Starck $1.21 .4 \%$ in $\mathrm{H}_{2} \mathrm{O}$ ) deposition the sample is mounted on a spincoater and abundantly sprayed with a 1:10 solution of PEDOT:PSS in 2 propanol using a glass nozzle. Immediately after wetting the sample is spincoated at $600 \mathrm{rpm}$ to yield a homogenous layer of PEDOT:PSS. Thickness of the PEDOT:PSS can be easily varied using different spin speeds. Deposition of PEDOT:PSS via spray coating before spinning is necessary to yield homogenous films [11] since other methods like drop casting lead to insufficient wetting. $100 \mathrm{~nm}$ thick silver top contacts are either thermally evaporated or DC sputtered onto the organic material through a shadow mask. Evaporation is performed at $0.1 \AA / \mathrm{s}$ for the first $10 \mathrm{~nm}$ and at $1.0 \AA / \mathrm{s}$ for the remaining $90 \mathrm{~nm}$. Sputtering is performed in five sputter cycles of $4 \mathrm{~min}$ at $1 \times 10^{2}$ mbar in an argon plasma. After top contact deposition solar cells are annealed at $140{ }^{\circ} \mathrm{C}$ for $5 \mathrm{~min}$ in ambient air.

\subsection{Solar cell characterization}

I $V$ characteristics are acquired with a Keithley 2400 Source Meter using a self made LabView program. Curves are measured in dark or under illumination with an AM 1.5G solar simulator. Light intensity is calibrated with a Fraunhofer Institute certified silicon reference cell with a KG5 filter and adjusted to $100 \mathrm{~mW} / \mathrm{cm}^{2}$. Solar cells are illuminated through a shadow mask, yielding an active area of $0.125 \mathrm{~cm}^{2}$. During long term measurements solar cells are stored in dark in ambient air.

\section{Results and discussion}

To examine the influence of a PEDOT:PSS interlayer between the polymer fullerene blend andthe top contact solar cells are fabricated with and without spray deposited PEDOT:PSS of approximately $40 \mathrm{~nm}$ thickness. Additionally, two different methods are used to apply the metal top contact, namely thermal evaporation and sputtering.

Fig. 1 gives an overview of the energy levels in an inverted P3HT PCBM solar cell. Hole blocking $\mathrm{TiO}_{2}$ collects electrons from the acceptor PCBM whereas holes are transported through P3HT towards PEDOT:PSS. The work functions of PEDOT:PSS and $\mathrm{TiO}_{2}$ are close to the highest occupied molecular orbital (HOMO) of PCBM and the lowest unoccupied molecular orbital (LUMO) of P3HT, respectively. This allows efficient electron injection into $\mathrm{TiO}_{2}$ whereas holes are collected at PEDOT:PSS.

Current voltage curves acquired under simulated solar illu mination $\left(100 \mathrm{~mW} / \mathrm{cm}^{2}\right)$ for different top contacts are shown in Fig. 2. The calculated characteristics are summarized in Table 1. The fill factor (FF) is defined as

$F F=\frac{I_{\mathrm{MPP}} V_{\mathrm{MPP}}}{I_{\mathrm{SC}} V_{\mathrm{OC}}}$,

where $I_{\mathrm{SC}}$ denotes the short cut current, $V_{\mathrm{OC}}$, the open circuit voltage, and $I_{\mathrm{MPP}}$ and $V_{\mathrm{MPP}}$ are the current and voltage at the maximum power point, respectively. Shunt resistance $\left(R_{\mathrm{sh}}\right)$

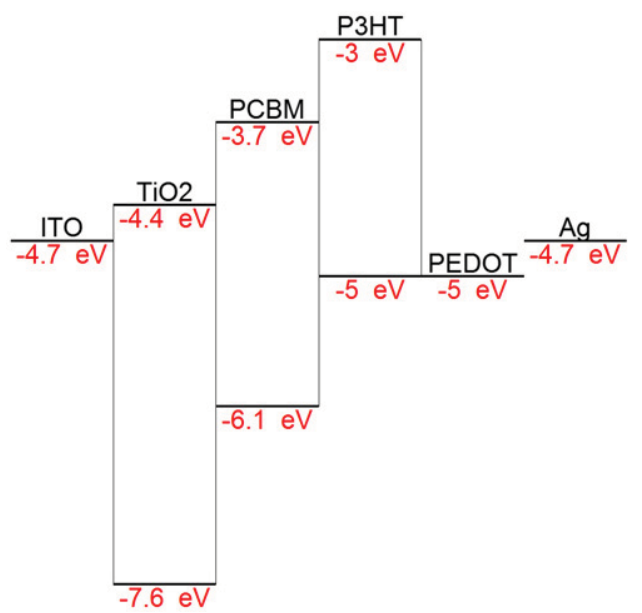

Fig. 1. Energy levels for an inverted P3HT-PCBM solar cell. Electrons are collected at the $\mathrm{TiO}_{2}$ bottom electrode and holes at the Ag top contact. Work function of the PEDOT:PSS interlayer matches the HOMO level of P3HT.

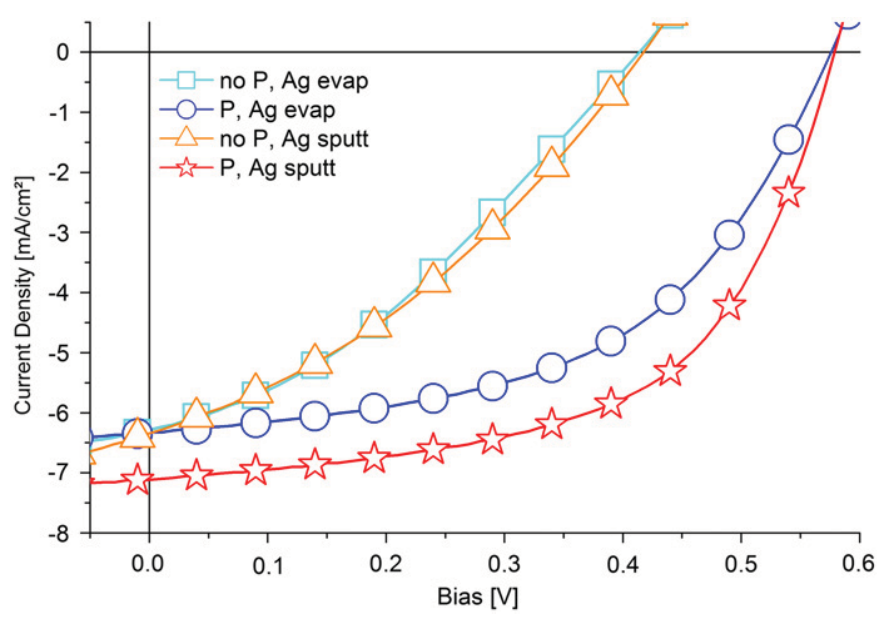

Fig. 2. Current-voltage characteristics under illumination with simulated AM 1.5G solar light $\left(100 \mathrm{~mW} / \mathrm{cm}^{2}\right)$. Data is shown for devices with PEDOT:PSS (circles: thermally evaporated $\mathrm{Ag}$; stars: sputtered $\mathrm{Ag}$ ) and without PEDOT:PSS (squares: thermally evaporated Ag; triangles: sputtered Ag). Devices with PEDOT:PSS exhibit higher $V_{O C}$ and FF.

Table 1

Calculated characteristics from current-voltage data acquired under simulated solar illumination. Values are given for solar cells with and without PEDOT:PSS and with thermally evaporated and sputtered Ag top contact.

\begin{tabular}{lllllll}
\hline & $\begin{array}{l}\text { PCE } \\
(\%)\end{array}$ & $\begin{array}{l}V_{\mathrm{OC}} \\
(\mathrm{V})\end{array}$ & $\begin{array}{l}\mathrm{I}_{\mathrm{SC}} \\
(\mathrm{mA} / \\
\left.\mathrm{cm}^{2}\right)\end{array}$ & $\begin{array}{l}\mathrm{FF} \\
(\%)\end{array}$ & $\begin{array}{l}R_{\mathrm{sh}} \\
\left(\Omega \mathrm{cm}^{2}\right)\end{array}$ & $\begin{array}{l}R_{\mathrm{s}} \\
\left(\Omega \mathrm{cm}^{2}\right)\end{array}$ \\
\hline $\begin{array}{l}\text { no PEDOT, } \\
\text { Ag evap }\end{array}$ & 0.92 & 0.41 & 6.29 & 34.1 & 231 & 26.9 \\
$\begin{array}{l}\text { PEDOT, Ag evap } \\
\text { no PEDOT, }\end{array}$ & 1.96 & 0.58 & 6.32 & 51.7 & 638 & 17.6 \\
$\begin{array}{l}\text { Ag sput } \\
\text { PEDOT, Ag sput }\end{array}$ & 0.96 & 0.42 & 6.34 & 34.7 & 154 & 14.7 \\
\hline
\end{tabular}

and series resistance $\left(R_{\mathrm{s}}\right)$ are obtained following the generalized Shockley diode model and calculated from linear fits to the $I V$ curves at small reverse bias and moderate forward bias, respectively.

Both devices without PEDOT:PSS exhibit reasonable photo currents but low FF of about $35 \%$, low $V_{\mathrm{OC}}$ of about $400 \mathrm{mV}$ and overall power conversion efficiencies (PCE) below $1 \%$. In contrast, 
the devices utilizing PEDOT:PSS provide PCE values of $1.96 \%$ and $2.44 \%$ and $\mathrm{FF}$ above $50 \%$ and $55 \%$ for evaporated and sputtered $\mathrm{Ag}$, respectively. Additionally, $V_{\mathrm{OC}}$ is enhanced to almost $0.6 \mathrm{~V}$ for both metal contacts due to the introduction of a PEDOT:PSS interlayer (Table 1).

We attribute the significantly better performance with PEDOT:PSS to two different effects. Ideally, the donor's HOMO and the acceptor's LUMO match the work functions of the hole and electron collecting electrodes, respectively. Ohmic contacts between the active materials and the external electrodes allow high photocurrents due to good charge extraction and high $V_{\mathrm{OC}}$ [12]. PEDOT:PSS exhibits a work function of $5.0 \mathrm{eV}$ matching the HOMO of P3HT better than the bare silver contact, which has a work function between 4.5 and $4.7 \mathrm{eV} \mathrm{[13]} \mathrm{(compare} \mathrm{Fig.} \mathrm{1).}$ Besides, PEDOT:PSS is known to accept holes from various donor materials even if the respective HOMO level does not match its work function [14]. The improved energy level matching is also reflected in relatively lower $R_{\mathrm{S}}$ values for the devices with PEDOT:PSS.

The second effect caused by PEDOT:PSS might be the protection of the P3HT PCBM layer during the top contact deposition. Sputtered Ag atoms are assumed to have higher energy when hitting the organic film (deposition rate about $1.0 \AA / \mathrm{s}$ ). Additionally, when sputtering, Ag clusters of different sizes are deposited next to single atoms [15]. Therefore, silver might penetrate into the active layer, especially in the case of sputtering [16]. This is also reflected in low $R_{\mathrm{sh}}$, indicating leakage of currents that limit the device performance and reduce the FF. $R_{\mathrm{sh}}$ is only $231 \Omega \mathrm{cm}^{2}$ for the evaporated $\mathrm{Ag}$ and even lower $\left(154 \Omega \mathrm{cm}^{2}\right)$ for the sputtered $\mathrm{Ag}$, probably due to the deeper penetration into the organic layer during the sputtering. Leakage currents are known to also affect $V_{\mathrm{OC}}$ if $R_{\mathrm{sh}}$ is reduced to a certain point [17], which also might partly explain the observed low $V_{\mathrm{OC}}$ values for the devices without PEDOT:PSS. However, we attribute the lower $V_{\mathrm{OC}}$ mainly to a non ideal work function of the freshly prepared Ag top contact as discussed later.

The higher photocurrent observed for the sputtered top contacts compared to the evaporated top contacts with PED OT:PSS is attributed to a better contact between silver and PEDOT:PSS. Very likely, sputtered Ag penetrates deeper into the PEDOT:PSS than the slowly evaporated Ag, allowing for an unhampered hole injection into the silver electrode. This is also reflected in lower $R_{\mathrm{s}}$ values for the sputtered top contacts for both solar cell types, with and without PEDOT:PSS. The reduced $R_{\mathrm{S}}$ is also the main reason for the high FF of the device with PEDOT:PSS and sputtered Ag.

Further hints for better hole collection with PEDOT:PSS are provided by the dark $I V$ curves in Fig. 3. The devices with PEDOT:PSS allow a much higher current in forward direction and an enhanced rectifying behavior. Moreover, the differences in shape of the $I V$ curves with and without PEDOT:PSS at moderate forward bias indicate space charge limits in the devices without PEDOT:PSS $[18,19]$. Since the electron collection in the $\mathrm{TiO}_{2}$ should be similar with and without PEDOT:PSS, and P3HT PCBM solar cells are known to be space charge limited mainly due to slow hole transport [20], we attribute this to space charge forming at the organic silver interface if no PEDOT:PSS is used. In contrast, if the PEDOT:PSS interlayer ensures an ohmic contact between the P3HT and the top electrode holes can exit the device unhamperedly.

The observed variations of reverse current in the dark $I \mathrm{~V}$ curves also correspond to deeper penetration of sputtered $\mathrm{Ag}$ into the organic layers. The device without PEDOT:PSS and the sputtered $\mathrm{Ag}$ exhibits the highest current at reverse bias, i.e. the highest leakage, whereas reverse current is significantly reduced if PEDOT:PSS protects the organic layer during sputtering.

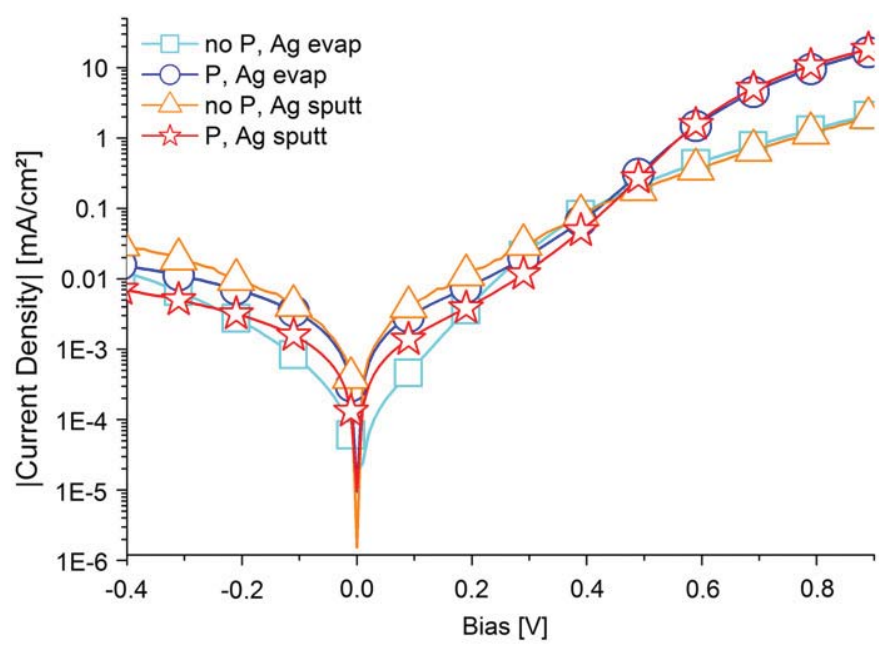

Fig. 3. Dark $I-V$ curves. Devices with PEDOT:PSS (circles: thermally evaporated $\mathrm{Ag}$; stars: sputtered $\mathrm{Ag}$ ) show higher currents in forward direction, a shape indicating no space charge limits. Contrarily, cells without PEDOT:PSS (squares: thermally evaporated $\mathrm{Ag}$; triangles: sputtered $\mathrm{Ag}$ ) seem to be space charge limited and allow only significantly lower forward currents.

The overall relatively low performance of about $2.5 \%$ compared to record values of $56 \%$ is attributed to two facts. First, our fabrication does not include any processing steps in an inert nitrogen atmosphere; both spincoating and annealing are per formed in ambient air. Secondly, the substrates used suffer at the elevated temperatures used for spray pyrolysis of the $\mathrm{TiO}_{2}$ layers. This increases series resistances caused by ITO which loses conductivity at high temperatures during $\mathrm{TiO}_{2}$ spray pyrolysis. Additionally, our active area of $0.125 \mathrm{~cm}^{2}$ is relatively large.

To investigate the influence of PEDOT:PSS on time evolution of device performance, a second experiment is carried out. Cells with evaporated $\mathrm{Ag}$ top contacts are fabricated and $I V$ characteristics are tested frequently under simulated solar light. Between the measurements, the cells are kept in dark in ambient air. Fig. 4 shows changes of the $V_{\mathrm{OC}}$ with time for representative devices with and without a PEDOT:PSS interlayer. The device with PEDOT:PSS exhibits a $V_{\mathrm{OC}}$ of $0.57 \mathrm{~V}$ immediately after production, which stays stable during the period of 10 days. Contrarily, the cell without PEDOT:PSS shows a low $V_{\mathrm{OC}}$ of around $0.25 \mathrm{~V}$ on the first day. During the following days the $V_{\mathrm{OC}}$ increases significantly but still remains below $0.5 \mathrm{~V}$ after 5 days. About 7 days after production the $V_{\mathrm{OC}}$ finally reaches $0.550 .6 \mathrm{~V}$. This is attributed to slow oxidation reactions of the $\mathrm{Ag}$, which should decrease the top contact's work function, yielding better matching of the P3HT HOMO level.

Both cell types with and without PEDOT:PSS are long term stable if stored in air. No significant changes in performance are observed after 80 days although the devices were not encapsulated or kept in a controlled atmosphere but stored in ambient atmosphere. Although PEDOT:PSS is known to cause quick degradation in non inverted [21] solar cells, this is not confirmed for our inverted devices with and without PEDOT:PSS. Thus, for the inverted structure, PEDOT:PSS helps to gain full performance immediately after fabrication, but has no detrimental effect on device stability.

\section{Conclusion}

A spray deposition technique for the application of aqueous solutions of PEDOT:PSS on hydrophobic surfaces is presented. This technique allows the fabrication of homogenous PEDOT:PSS layers on top of P3HT PCBM, which is beneficial for inverted solar cells. Devices with PEDOT:PSS exhibit full performance 


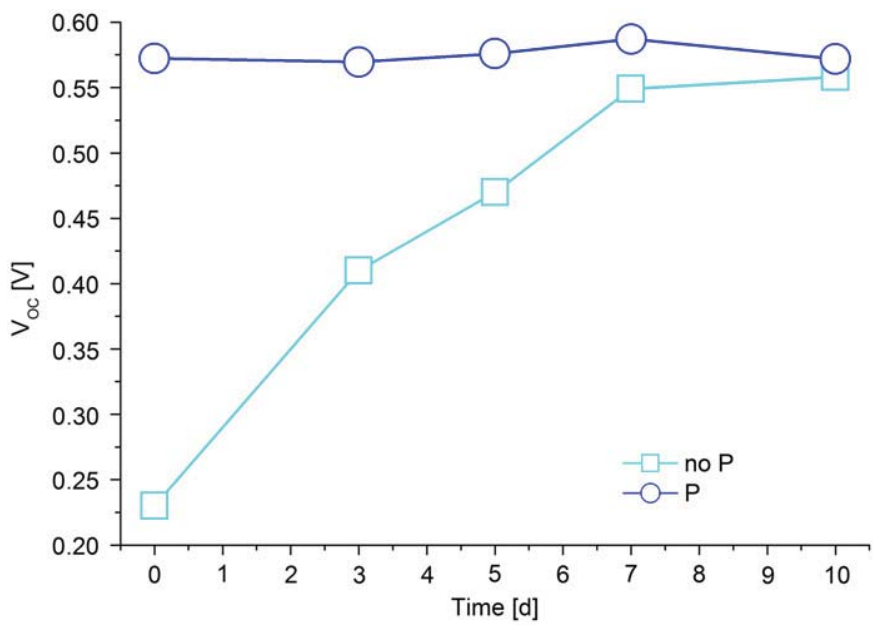

Fig. 4. Time evolution of $V_{\mathrm{OC}}$ for device with (circles) and without (squares) PEDOT:PSS. Devices are fabricated with a thermally evaporated Ag top contact.

immediately after fabrication and allow slightly higher $I_{\mathrm{SC}}$. PEDOT:PSS allows efficient hole collection and protects the organic material during the top contact deposition. Both, cells with and without PEDOT:PSS, show long term stability and do not significantly decrease after 80 days of storage in air. The techniques presented are a further step towards easy and cheap roll to roll fabrication. P3HT PCBM and PEDOT:PSS are solution processed and no inert nitrogen atmosphere is needed.

\section{Acknowledgements}

This work has been supported by the German Excellence Initiative of the Deutsche Forschungsgemeinschaft (DFG) via the "Nanosystems Initiative, Munich (NIM)" and the German Research Foundation in the program, "SPP1355: elementary processes of organic photovoltaics".

\section{References}

[1] C.W. Tang, 2-Layer organic photovoltaic cell, Appl. Phys. Lett. 48 (1986) 183-185.

[2] G. Dennler, M.C. Scharber, T. Ameri, P. Denk, K. Forberich, C. Waldauf, C.J Brabec, Design rules for donors in bulk-heterojunction tandem sola cells-towards 15\% energy-conversion efficiency, Adv. Mater. 20 (2008) 579-583.

[3] G. Dennler, M.C. Scharber, C.J. Brabec, Polymer-fullerene bulk-heterojunction solar cells, Adv. Mater. 21 (2009) 1323-1338.

[4] C. Waldauf, M. Morana, P. Denk, P. Schilinsky, K. Coakley, S.A. Choulis, C.J. Brabec, Highly efficient inverted organic photovoltaics using solution based titanium oxide as electron selective contact, Appl. Phys. Lett. 89 (2006) 233517-1-233517-3.

[5] Y. Yoshida, S. Tanaka, Y. Fujita, I. Hiromitsu, Organic thin-film solar cells with a $\mathrm{Cu}$ anode: improvement of the photovoltaic properties on aging in air. J. Appl. Phys. 106 (2009) 064510-1-064510-8.

[6] A.J. Medford, M.R. Lilliedal, M. Joergensen, D. Aaro, H. Pakalski, J. Fyenbo, F.C. Krebs, Grid-connected polymer solar panels: inital considerations of cost, lifetime, and practicality, Optics Express 18 (2010) A272-A285.

[7] F.C. Krebs, S.A. Gevorgyan, J. Alstrup, A roll-to-roll process to flexible polymer solar cells: model studies, manufacture and operational stability studies, J. Mater. Chem. 19 (2009) 5442-5451.

[8] F.C. Krebs, T. Tromholt, M. Jorgensen, Upscaling of polymer solar cell fabrication using full roll-to-roll processing, Nanoscale 2 (2010) 873-886.

[9] H.C. Hesse, J. Weickert, M. Al-Hussein, L. Dossel, X.L. Feng, K. Mullen, L Schmidt-Mende, Discotic materials for organic solar cells: effects of chemical structure on assembly and performance, Sol. Energy. Mater. Sol. Cells 94 (2010) 560-567.

[10] T. Kuwabara, H. Sugiyama, T. Yamaguchi, K. Takahashi, Inverted-type bulk-heterojunction organic solar cell using electrodeposited titanium oxide thin films as electron collector electrode, Thin Solid Films 517 (2009) 3766-3769.

[11] Y.F. Lim, S. Lee, D.J. Herman, M.T. Lloyd, J.E. Anthony, G.G. Malliaras, Spraydeposited poly(3,4-ethylenedioxythiophene): poly(styrenesulfonate) top electrode for organic solar cells, Appl. Phys. Lett. 93 (2008) 193301-1-193301-3.

[12] B. de Boer, A. Hadipour M.M. Mandoc, T van Woudenbergh, P.W.M. Blom, Tuning of metal work functions with self-assembled monolayers, Adv. Mater. 17 (2005) 621-625.

[13] David R. Lide, CRC Handbook of Chemistry and Physics, vol. 90, Taylor \& Francis, 2009, pp. 12-114.

[14] M.C. Scharber, D. Wuhlbacher, M. Koppe, P. Denk, C. Waldauf, A.J. Heeger, C.L. Brabec, Design rules for donors in bulk-heterojunction solar cells-towards $10 \%$ energy-conversion efficiency, Adv. Mater. 18 (2006) 789-794.

[15] R. Willecke, F. Faupel, Diffusion of gold and silver in bisphenol, a polycarbonate, Macromolecules 30 (1997) 567-573.

[16] A.C. Durr, F. Schreiber, M. Kelsch, H.D. Carstanjen, H. Dosch, Morphology and thermal stability of metal contacts on crystalline organic thin films, Adv. Mater. 14 (2002) 961-963.

[17] Jenny Nelson, Physics of Solar Cells, 1, World Scientific Pub Co., 2003, pp. 1-16.

[18] W.U. Huynh, J.J. Dittmer, N. Teclemariam, D.J. Milliron, A.P. Alivisatos, K.W.J. Barnham, Charge transport in hybrid nanorod-polymer composite photovoltaic cells, Phys. Rev. B 67 (2003) 115326-1-115326-12.

[19] T. Dobbertin, O. Werner, J. Meyer, A. Kammoun, D. Schneider, T. Riedl, E. Becker, H.H. Johannes, W. Kowalsky, Inverted hybrid organic light-emitting device with polyethylene dioxythiophene-polystyrene sulfonate as an anode buffer layer, Appl. Phys. Lett. 83 (2003) 5071-5073.

[20] V.D. Mihailetchi, H.X. Xie, B. de Boer, L.J.A. Koster, P.W.M. Blom, Charge transport and photocurrent generation in poly(3-hexylthiophene): methanofullerene bulk-heterojunction solar cells, Adv. Funct. Mater. 16 (2006) 699-708.

[21] M. Jorgensen, K. Norrman, F.C. Krebs, Stability/degradation of polymer solar cells, Sol. Energ. Mater. Sol. Cells. 92 (2008) 686-714. 